\title{
Crimean-Congo Hemorrhagic Fever Virus and Borrelia burgdorferi sensu lato in Ticks from Kosovo and Albania
}

\author{
Kurtesh Sherifi', Agim Rexhepi't, Kristaq Berxholi', Blerta Mehmedi', Rreze M. Gecaj', \\ Zamira Hoxha ${ }^{2}$, Anja Joachim ${ }^{3}$ and Georg G. Duscher ${ }^{3 *}$ \\ ${ }^{1}$ Faculty of Agriculture and Veterinary, University of Prishtina "Hasan Prishtina", Pristina, Kosovo, ${ }^{2}$ Faculty of Veterinary \\ Medicine, Agricultural University of Tirana, Tirana, Albania, ${ }^{3}$ Department of Pathobiology, Institute of Parasitology, \\ University of Veterinary Medicine Vienna, Vienna, Austria
}

\section{OPEN ACCESS}

Edited by:

Rodrigo Guabiraba, INRA Centre Val de Loire, France

Reviewed by:

Agustín Estrada-Peña,

University of Zaragoza, Spain

Saravanan Thangamani, University of Texas Medical Branch, United States

*Correspondence: Georg G. Duscher georg.duscher@vetmeduni.ac.at

tThese authors have contributed equally to this work.

Specialty section:

This article was submitted to Veterinary Infectious Diseases,

a section of the journal

Frontiers in Veterinary Science

Received: 27 October 2017 Accepted: 19 February 2018

Published: 06 March 2018

Citation:

Sherifi K, Rexhepi A, Berxholi K, Mehmedi B, Gecaj RM, Hoxha Z, Joachim A and Duscher GG (2018)

Crimean-Congo Hemorrhagic

Fever Virus and Borrelia burgdorferi sensu lato in Ticks from Kosovo and Albania.

Front. Vet. Sci. 5:38 doi: 10.3389/fvets.2018.00038
Tick-borne diseases pose a serious threat to human health in South-Eastern Europe, including Kosovo. While Crimean-Congo hemorrhagic fever (CCHF) is a well-known emerging infection in this area, there are no accurate data on Lyme borreliosis and tickborne encephalitis (TBE). Therefore, we sampled and tested 795 ticks. Ixodes ricinus $(n=218)$, Dermacentor marginatus $(n=98)$, and Haemaphysalis spp. $(n=24)$ were collected from the environment by flagging (all from Kosovo), while Hyalomma marginatum ( $n=199$ from Kosovo, all from Kosovo) and Rhipicephalus bursa ( $n=130,126$ from Albania) could be collected only by removal from animal pasture and domestic ruminants. Ticks were collected in the years 2014/2015 and tested for viral RNA of CCHF and TBE viruses, as well as for DNA of Borrelia burgdorferi sensu lato by real-time PCR. In Kosovo, nine ticks were positive for RNA of Crimean-Congo hemorrhagic fever virus and seven for DNA of $B$. burgdorferi s. I. None of the ticks tested positive for TBEV. $\mathrm{CCHF}$ virus was detected in one $\mathrm{H}$. marginatum male specimen collected while feeding on grazing cattle from the Prizren region and in eight $R$. bursa specimens (five females and three males collected while feeding on grazing sheep and cattle) from the Prishtina region (Kosovo). B. burgdorferi s. I. was detected in seven questing ticks (four male and one female $D$. marginatus, two I. ricinus one female and one male) from the Mitrovica region (Kosovo). Our study confirmed that CCHF virus is circulating in Kosovo mainly in $H$. marginatum and $R$. bursa in the central areas of the country. B. burgdorferi s. I. was found in its major European host tick, I. ricinus, but also in D. marginatus, in the north of the Kosovo. In order to prevent the spread of these diseases and better control of the tick-borne infections, an improved vector surveillance and testing of ticks for the presence of pathogens needs to be established.

Keywords: Crimean-Congo hemorrhagic fever, Lyme borreliosis, Hyalomma marginatum, Dermacentor marginatus, Ixodes ricinus

\section{INTRODUCTION}

Crimean-Congo hemorrhagic fever virus (CCHFV) is a tick-borne pathogenic member of the Bunyavirales order, Nairoviridae family, genus Orthonairovirus (1). CCHFV is present in different countries in Africa, Asia, and Europe (2). The occurrence of CCHFV in Europe corresponds with the circulation of Hyalomma marginatum ticks, which are both reservoirs and vectors of the virus (3). 
In the southeast of Europe Crimean-Congo hemorrhagic fever (CCHF) is sporadic or endemic in Bulgaria, Kosovo, Albania, Greece, and Turkey (4-6). In Kosovo, 304 persons were diagnosed with CCHF with 21\% case fatality rate between 1954 and 2014 (7). In about $50 \%$ of the Kosovo regions, CCHFV is widespread with hyperendemic areas in the municipalities of Malishevë, Rahovec, Suharekë, and Klinë (Prizren, Gjakove, and Peja regions). The prevailing CCHF season is between May and July, which corresponds with the peak activity of $H$. marginatum ticks. CCHF human cases in Albania occurred mostly in the region bordering Kosovo, respectively, in Kukes and Has municipalities (8).

In a study conducted by Sherifi et al. (9) who analyzed 1,102 ticks by RT-PCR, 3.6\% were positive for CCHFV, mostly H. marginatum ( $9.8 \%$ or $29 / 297$ tick samples in endemic areas) and in Rhipicephalus bursa (9.3\% or 10/108 samples in non-endemic areas), while only in one, Ixodes ricinus viral RNA of CCHFV was detected. In 2013, Kosovo experienced an outbreak of CCHF in humans with 26 cases confirmed clinically and by RT-PCR, 13 of whom have died (10). In Albania, $385 \mathrm{H}$. marginatum in 73 pools and $277 R$. bursa in 59 pools were sampled and tested in the years 2007-2010, and $11.8 \%$ of the pools of $R$. bursa were positive for CCHFV by RT-PCR (11).

In Kosovo and Albania, two strains of CCHF virus, Europe 1 and 2, are circulating (Clade V and VI). The strain Europe 1 (Clade V) appears to be transmitted by H. marginatum ticks and is highly pathogenic for humans, while the strain Europe 2 (Clade VI) is found exclusively in R. bursa ticks and is associated with the subclinical or mild cases of CCHF in humans $(9,11)$. Also, in Greece and Turkey, strain Europe 2 (Clade VI) was from ticks and humans (including the prototype strain AP92) $(12,13)$.

Lyme borreliosis is a widespread tick-borne disease caused by the pathogen Borrelia burgdorferi sensu lato and its predominant vector in Europe is I. ricinus (14). Borreliae are Gram-negative bacteria of the family Spirochaetaceae. B. burgdorferi s. 1. can be divided into different genospecies, of which B. afzelii, B. burgdorferi sensu stricto, $B$. garinii and, possibly, $B$. valaisiana have pathogenic significance (15). B. afzelii is more widespread in the Northern, Central, and Eastern parts of Europe and B. garinii in the Western parts (16). The disease can manifest itself in a variety of disease forms $(17,18)$. About 65,000 human cases of Lyme borreliosis are reported annually in Europe (19). The prevalence of Borrelia in ticks in Europe is $13.7 \%$, whereas the prevalence is higher in adults (18.6\%) than in nymphs (10.1\%) (20). In the city of Hannover (Germany), infection rates were $33.3 \%$ in adult I. ricinus ticks, $20.3 \%$ in nymphs, and $25.8 \%$ in larvae (21). In I. ricinus adults collected in Bulgaria, the prevalence of $B$. burgdorferi s. 1. was almost $40 \%$, while B. afzelii was the main species with $>50 \%(22)$.

In Kosovo, no data about the prevalence of Lyme borreliosis in humans or B. burgdorferi in ticks are available. In the Clinic of Infectious Diseases at the University Clinical Center of Kosovo, 30 patients were diagnosed clinically by ELISA for Lyme borreliosis in 2015, thus confirming the presence of the pathogen in the area. A number of infections in Kosovo probably remain undiagnosed.

Tick-borne encephalitis (TBE) is a viral tick-borne disease that is present in endemic regions in different countries of Europe and Asia. TBEV (family Flaviviridae) encompass three subtypes, the Western subtype, which is predominant in central, eastern, and northern Europe; the Siberian subtype, endemic in eastern Europe, Russia, and northern Asia; and the Far Eastern subtype, endemic in eastern Russia and some parts of China and Japan $(23,24)$. I. ricinus is a vector of TBEV in central, northern, and eastern Europe and I. persulcatus (in northeastern Europe and northern and central Asia). Small rodents are the competent reservoir hosts of TBEV. Humans usually acquire the infection by tick bites and consumption of raw dairy products derived from infected animals (25). Several thousand cases with neuroinvasive illness are recorded in Europe and Asia annually, which also represent an international public health problem because of increasing mobility and travels to endemic regions (24). In Eastern Europe, TBE was reported from Slovenia, Croatia, Bosnia, Serbia, Albania, and Greece (24-26). TBEV prevalence in tick populations was determined for endemic regions like Austria (0.44-6.2\%), Finland (0.07-2.57\%), Germany (0.3-5.3\%), and Slovenia (0.43\%) (27-30). In Albania, 82 TBE cases (described as nonbacterial meningoencephalitis) were reported from 1983 to 1990 (31, 32). From 1990 to 1996, 67 cases were registered. Mostly people living in rural areas were infected by ingestion of unpasteurized milk and dairy products (Berxholi 2016, personal communication).

The aim of the study was to determine the tick species and their infection rates for CCHFV, B. burgdorferi s. 1., and TBE, where especially for latter pathogen, no data on humans or ticks Kosovo are available so far, in different regions of Kosovo and Albania.

\section{MATERIALS AND METHODS}

\section{Study Area and Tick Collection}

Kosovo has a total area of $10,900 \mathrm{~km}^{2}$, with approximately $40 \%$ fragmented agricultural land surrounded by $60 \%$ mountains with sea level between 276 and 2,656 m. The climate is Mediterranean continental and European continental (33). Albania borders Kosovo to the South-West has a total area of $28,748 \mathrm{~km}^{2}$ and $70 \%$ of the country is mountainous. The climate is typically Mediterranean except for the most north-western parts with high altitude areas (34). In Kosovo, ticks were collected in 15 villages of four regions (Prizren, Prishtina, Mitrovice, and Ferizaj) during April-June and September-October 2014-2015. In this area, a continental climate dominates, characterized by cold winters and hot summers. The maximum temperatures are reached during the summer, averaging $+25^{\circ} \mathrm{C}$, while the minimum temperatures are displayed in January, at an average value of $-3^{\circ} \mathrm{C}$. Atmospheric precipitation is at an average of $751 \mathrm{~mm}$ per year. The agricultural land is fragmented and the villages are surrounded by low mountains and have lands with bushes. The ticks were randomly collected in the localities with an altitude between 450 and $700 \mathrm{~m}$. In Albania, ticks were collected in four villages of three different municipalities in the North-East (Kukes), the North-West (Lezhe), and the South of the country (Gjirokaster). Due to logistic constraints, the sample size did not reach the scheduled amount. However, I. ricinus, Dermacentor marginatus, and Haemaphysalis spp. were collected by flagging, while $H$. marginatum and $R$. bursa were sampled from the ground mostly on animal pastures or directly 
from livestock in order to remove ticks from the infested animals by the use of paired forceps. Latter two tick species are more likely to be found on host (35), consequently, sampling during feeding on host or on the pasture close to the hosts deliver more ticks in shorter time, which in turn makes comparison to flagged ticks almost impossible. To evaluate a possible spreading of $\mathrm{CCHF}$ virus from the known endemic areas Prizren and Prishtina to other neighboring regions (Mitrovica and Ferizaj) through the movement of domestic animals, we have selected randomly the sites for tick collection near domestic animals farm. During the tick collection, adequate personal protection was applied. Ticks were placed into $2 \mathrm{ml}$ cryovials and stored at $-80^{\circ} \mathrm{C}$ in the veterinary laboratory in Prishtina. Identification of tick species and sex determination were done under a stereomicroscope using the key of Estrada-Peña et al. (36).

\section{RNA/DNA Extraction from Ticks}

The extraction was carried out under the same conditions and in the same facility as used for human samples tested for CCHFV. Single whole ticks were placed in a $2 \mathrm{ml}$ Eppendorf tube containing three to five steel beads ( $7 \mathrm{~mm}$, Qiagen, Hilden, Germany), frozen on liquid nitrogen, and directly granulated in a TissueLyser LT (Qiagen, Hilden, Germany) with a $-20^{\circ} \mathrm{C}$ pre-cooled rotor at $50 \mathrm{~Hz}$ for $2-5 \mathrm{~min}$. Repeated freezing and lysis was necessary in some cases. The samples were then re-suspended in 300-500 $\mu \mathrm{l}$ PBS (depending on tick size) containing 10\% fetal calf serum, $500 \mathrm{IU} / \mathrm{ml}$ penicillin, and $500 \mu \mathrm{g} / \mathrm{ml}$ amphotericin, and centrifuged at $2,000 \times g$. For viral RNA extraction, $200 \mu \mathrm{l}$ of the supernatant was diluted in $200 \mu \mathrm{l}$ distilled water including carrier RNA and proteinase K (RTP DNA/RNA Virus Mini Kit, Stratec, Birkenfeld, Germany), following sample inactivation for $10 \mathrm{~min}$ in $95^{\circ} \mathrm{C}$ and DNA/RNA extraction according to the manufacturer's instructions.

\section{Reverse Transcriptase-PCR Detection for CCHFV RNA and TBEV RNA}

For the first round of the RT-PCR, $2 \mu \mathrm{l}$ RNA each of up to five single tick extractions were pooled $(10 \mu \mathrm{l})$ to obtain 160 pools for detection of CCHF virus. Only for CCHF virus-positive pools, single tick diagnostic PCRs were subsequently conducted. The RT-PCRs for CCHFV (Europa 1 (Clades V) and Europa 2 (Clades VI) or variant AP92) were carried out using the RealStar ${ }^{\circledR}$ CCHFV RT-PCR Kit 1.0 (Altona Diagnostics, Hamburg, Germany), according to the manufacturer's instructions. For the detection of TBEV (European, Far Eastern, and Siberian viral subtypes) in ticks, $1 \mu \mathrm{l}$ DNA/RNA eluates each of up to four single tick extractions were pooled $(4 \mu \mathrm{l})$ to obtain a total of 200 pools and RT-PCR was performed using the ixSave ${ }^{\circledR}$ TBE real-time RT-PCR Kit TM (Gerbion, Kornwestheim, Germany). Sequence amplification were performed and analyzed on a Rotor-Gene $\mathrm{Q}^{\circledR}$ (Qiagen, Hilden, Germany).

\section{Quantitative Real-time PCR for B. burgdorferi s. I. DNA}

For the detection of $B$. burgdorferi s. $1 ., 1 \mu \mathrm{l}$ DNA/RNA eluates each of up to four single tick extractions were pooled $(4 \mu \mathrm{l})$ to obtain 200 pools and analyzed with ixSave ${ }^{\circledR}$ Borrelia real time PCR Kit (Gerbion, Kornwestheim, Germany) on a Rotor-Gene $\mathrm{Q}^{\circledR}$ (Qiagen, Hilden, Germany). Similar to the CCHFV procedure, only the single tick extracts of positive pools were further analyzed individually.

\section{RESULTS}

For both sampling strategies, only adult ticks could be collected. The most abundant questing tick species in Kosovo collected by flagging $(n=340)$ was $I$. ricinus $(64.2 \%)$, followed by D. marginatus (28.8\%) and Haemaphysalis spp. (7\%) (Table 1). Of these, seven of them were positive for B. burgdorferi s. 1., but none of them was positive for CCHFV and TBEV (Table 1).

Hyalomma marginatum ( $n=199$ from Kosovo) and $R$. bursa ( $n=130$ from Kosovo and 126 from Albania) that are competent vector for CCHFV could not be sampled by flagging; instead, $132 \mathrm{H}$. marginatum were picked from the ground or from animal pasture and 67 were collected from domestic ruminants. One of the latter ( $H$. marginatum) was positive on CCHFV. Of the 130 tested $R$. bursa ticks from Kosovo collected from domestic animals, eight were positive for CCHFV (Table 1).

In Albania, none of the 126 collected $R$. bursa ticks was positive for the investigated pathogens.

Overall, CCHFV RNA was detected in one H. marginatum and eight $R$. bursa specimens (total of 9 ticks) collected while feeding on nine different individual animals (6 cattle and 3 sheep). In the Prizren region (village Senike, Malishevë municipality), one male of nine $H$. marginatum ticks collected from grazing cattle in April 2014 was positive. In the second region of Kosovo where CCHF virus-positive ticks were found, Prishtina, all eight positive $R$. bursa while feeding (five female and three male) were collected from grazing sheep and cattle in June 2014.

Borrelia burgdorferi s. 1 . was detected in seven of the 340 flagged ticks $(2.0 \%)$ from Kosovo and was found only in the Mitrovica region (northern Kosovo). Two of 134 I. ricinus (1.5\%) and five of 98 D. marginatus (5.1\%), collected in May 2014 by flagging tested positive for B. burgdorferi s. 1 . None of the ticks (H. marginatum, $R$. bursa) collected from the pastures or animals were positive for this pathogen.

\section{DISCUSSION}

Crimean-Congo hemorrhagic fever virus is present on the Balkan Peninsula, and at least in some regions it appears to be closely linked to the presence of $H$. marginatum ticks as its main vector and reservoir (37). The detection of CCHFV in $\mathrm{H}$. marginatum ticks from the southwestern Prizren region and in $R$. bursa from the northeastern Prishtina region of Kosovo, which are the dominant tick species in the respective regions, provides strong evidence of the continuous presence of CCHFV in the country. In our study, nine of tested ticks were positive for viral RNA of CCHFV, although based on the low amount of ticks sampled, any conclusions on the actual risk has to be done with caution. Additionally, it has to be stated that due to the different sampling method, no real prevalence data can be drawn for CCHFV. But, the results indicate the circulation of this virus in particular on 
TABLE 1 | Ticks and infections rates for Borrelia burgdorferi s. I. and Crimean-Congo hemorrhagic fever virus (CCHFV) in different regions of Kosovo.

\begin{tabular}{|c|c|c|c|c|c|c|c|c|}
\hline Ticks & Sample collection & $N$ ticks & Mitrovice & Prishtina & Prizren & Ferizaj & Total & Detection of positive individuals \\
\hline \multirow[t]{4}{*}{ Ixodes ricinus } & Vegetation & Total & 134 & 29 & 16 & 29 & 195 & \\
\hline & Vegetation & Females & $67^{\star}$ & 23 & 15 & 19 & 124 & ${ }^{\star} B$. burgdorferi $(N=1)$ \\
\hline & Vegetation & Males & $54^{*}$ & 6 & 1 & 10 & 71 & ${ }^{\star} B$. burgdorferi $(N=1)$ \\
\hline & & Subtotal & 134 & 29 & 16 & 39 & 218 & \\
\hline \multirow[t]{4}{*}{ Dermacentor marginatus } & Vegetation & Total & 98 & 0 & 0 & 0 & 98 & \\
\hline & Vegetation & Females & $44^{*}$ & 0 & 0 & 0 & 44 & ${ }^{\star} B$. burgdorferi $(N=1)$ \\
\hline & Vegetation & Males & $54^{*}$ & 0 & 0 & 0 & 54 & ${ }^{\star} B$. burgdorferi $(N=4)$ \\
\hline & & Subtotal & 98 & 0 & 0 & 0 & 98 & \\
\hline \multirow[t]{4}{*}{ Haemaphysalis spp. } & & Total & 20 & 4 & 0 & 0 & 24 & \\
\hline & Vegetation & Females & 8 & 2 & 0 & 0 & 10 & \\
\hline & Vegetation & Males & 12 & 2 & 0 & 0 & 14 & \\
\hline & & Subtotal & 20 & 4 & 0 & 0 & 24 & \\
\hline \multirow[t]{7}{*}{ Hyalomma marginatum } & Field & Total & 0 & 0 & 132 & 0 & 132 & \\
\hline & Field & Females & 0 & 0 & 66 & 0 & 66 & \\
\hline & Field & Males & 0 & 0 & 66 & 0 & 66 & \\
\hline & Host & Total & 7 & 47 & 9 & 4 & 67 & \\
\hline & Host & Females & 0 & 15 & 1 & 0 & 16 & \\
\hline & Host & Males & 7 & 32 & $8^{*}$ & 4 & 51 & ${ }^{*} \mathrm{CCHFV}(N=1)$ \\
\hline & & Subtotal & 7 & 47 & 141 & 4 & 199 & \\
\hline \multirow[t]{7}{*}{ Rhipicephalus bursa } & Field & Total & 0 & 0 & 0 & 0 & 0 & \\
\hline & Field & Females & 0 & 0 & 0 & 0 & 0 & \\
\hline & Field & Males & 0 & 0 & 0 & 0 & 0 & \\
\hline & Host & Total & 0 & 116 & 0 & 14 & 130 & \\
\hline & Host & Females & 0 & $60^{\star}$ & 0 & 12 & 72 & ${ }^{*} \mathrm{CCHFV}(N=5)$ \\
\hline & Host & Males & 0 & $56^{\star}$ & 0 & 2 & 58 & ${ }^{\star} \mathrm{CCHFV}(N=3)$ \\
\hline & & Subtotal & 0 & 116 & 0 & 14 & 130 & \\
\hline
\end{tabular}

*Detection of positive individual ticks for B. burgdorferi s. I. and CCHFV.

these locations. For a more accurate estimation, a higher number of ticks has to be investigated. The Prizren region encompasses the municipalities of Malishevë, Rahovec, Suharekë, and Klinë, which are known endemic regions for CCHF. In the last CCHF disease outbreak in this region in 2013, 13 out of 26 patients clinically and laboratory diagnosed with CCHF died (10). In the present study, one $H$. marginatum tick out of nine collected in the village of Senik, Malishevë municipality, harbored CCHFV RNA. Sherifi et al. (9) collected H. marginatum ticks in Malishevë municipality in 2012 and found $8.6 \%$ to be positive for CCHFV. In the Klinë municipality, $4 \%$ of the ticks harbored RNA of CCHFV, seven H. marginatum, and one I. ricinus. Malishevë, Klinë, Suharekë, and Rahovec municipalities are the CCHF endemic areas in Kosovo, and every 3-5 years, disease outbreaks with high mortality rates are recorded. The most affected groups are agricultural workers and animal farmers.

The highest amount of CCHFV-positive ticks in the Prishtina region occurred in the village of Hajvali, with 8 of 115 tested $R$. bursa. In this region, no human cases of CCHF have been reported so far, which may be due to a lower affinity of $R$. bursa to humans compared to $H$. marginatum, or the presence of different CCHFV strains. Nevertheless, both tick species represent competent vectors and are of enormous importance in order to estimate any risk outgoing from those ticks. Interestingly, flagging for these two species is known to beless effective $(35,38)$, and sampling from the hosts is the method of choice to obtain those ticks (38-41). Collection of ticks from the hosts is sometimes used for other tick species as well $(42,43)$ although environmental collection closer reflects the real situation and, therefore, should be preferred (44).
Anyhow, the collection and analysis of R. bursa and H. marginatum is of enormous interests and can be easily done from the hosts, but the abundance cannot directly be compared with the flagged tick samples. Hence, cross-over contamination of the animal blood cannot be excluded. However, analyzing these two species from Kosovo may reveal two CCHFV strains. One is "Kosova Hoti," which was also isolated from the humans during the outbreak in Kosovo in 2001. It belongs to the Europe/Turkey group with high similarities to the Russian isolate "Drosdov strain." This strain clusters with Europa 1 (Clade V) and is highly pathogenic for humans, and the competent biological vector is assumed to be $H$. marginatum. The second CCHFV strain is circulating between $R$. bursa and animals in Kosovo and is related to a strain isolated in the Greece (AP92). This strain clusters with Europe 2 (Clade VI) and is low pathogenic or non-pathogenic for humans $(9,45)$. A sero-prevalence study in south Albania and the Former Yugoslav Republic of Macedonia (FYROM) for the detection of anti-CCHF IgG antibodies in domestic ruminants revealed a high rate of sero-positivity of 23\% in Albania and 49\% in FYROM (46), indicating that CCHFV is circulating in domestic animals and ticks in these two countries.

The presence of CCHFV in ticks in Kosovo and Albania and the local outbreaks in humans every 3-5 years in southwestern Kosovo and North Albania are a strong indication that a CCHFV "high pathogenic" strain persists in those regions and correlates with the abundance of $H$. marginatum ticks. The circulation of a CCHFV "low" or "nonpathogenic" strain in northeastern Kosovo (near Prishtina) and in southern Albania correlates with the distribution of $R$. bursa ticks. We could not detect CCHFV neither in 
ticks from Mitrovica and Ferizaj, which are neighboring regions of Prizren and Prishtina, nor in ticks from Albania. The possibility of the spread of CCHFV into other regions and countries is very high, taking into account the movements of domestic and wild animals, as well as migratory birds. In the present study, testing of ticks near the endemic CCHF regions in Kosovo, namely in Mitrovice and Ferizaj, indicates that the distribution of H. marginatum in these two regions is very scarce, and none of them was infected with CCHFV. The spreading of infected $H$. marginatum females attached to domestic animals to another region can occur at any time in Kosovo and neighboring countries, but it of course then depends on the tick's ability to adapt to new environmental conditions and to continue its life cycle.

The spread of CCHFV in different regions is possible through the migratory birds, which can carry infected ticks. The detection of CCHFV in such animals in Morocco indicates a risk of spreading the virus to Europe, and this assumption is also supported by the detection of the first human cases of CCHF in Spain in August $2016(47,48)$.

For further studies and in order to prevent the spread of this dangerous infectious agent, it will be very important to survey a possible re-assortment (49) of the two different CCHFV strains circulating in Kosovo and the neighboring countries and its role in the pathogenicity for humans in combination with tick surveillance and control, treatment of domestic animals with acaricides in endemic regions, as well as the detection of CCHFV RNA in ticks.

Lyme borreliosis is present in Kosovo and is related to the distribution of $I$. ricinus and D. marginatus ticks. Epidemiological data for infections of humans do not exist in the country due to the absence of a monitoring program. In the present study, $2 \%$ of 340 flagged tested ticks were positive for B. burgdorferi s. 1 . and found only in the Mitrovice region, were the most abundant ticks species were $I$. ricinus and D. marginatus. Of the 134 collected, I. ricinus $1.5 \%$ and the $98 \mathrm{D}$. marginatus $5.1 \%$ were positive for B. burgdorferi s. I. D. marginatus might play a role as a secondary vector in some ecosystems regarding B. burgdorferi s. 1., as stated from Bulgaria (50), but this has to be proven with transmission studies.

In the present study, TBEV was not detected in ticks from Kosovo or Albania, probably because even in highly endemic

\section{REFERENCES}

1. International Committee on Taxonomy of Viruses. Virus Taxonomy: 2016 Release. (2016). Available from: https://talk.ictvonline.org/taxonomy/

2. Hoogstraal H. The epidemiology of tick-borne Crimean-Congo hemorrhagic fever in Asia, Europe and Africa. J Med Entomol (1979) 15:307-417. doi:10.1093/jmedent/15.4.307

3. Whitehouse CA. Crimean-Congo hemorrhagic fever. Antiviral Res (2004) 64:145-60. doi:10.1016/j.antiviral.2004.08.001

4. Humolli I, Dedushaj I, Avsic-Zupanc T, Mucaj S. Epidemiological, serological and herd immunity of Crimean - Congo haemorrhagic fever in Kosovo. Med Arh (2010) 64:91-3.

5. Maltezou HC, Andonova L, Andraghetti R, Bouloy M, Ergonul O, Jongejan F, et al. Crimean-Congo hemorrhagic fever in Europe: current situation calls for preparedness. Euro Surveill (2010) 15:19505.

6. Papa A, Tzala E, Maltezou H. Crimean-Congo hemorrhagic fever virus, Northeastern Greece. Emerg Infect Dis (2011) 17:141-3. doi:10.3201/eid1701.100073 areas, TBEV distribution follows a scattered and very focal pattern (51). Transmission foci are mostly restricted to small areas and the detection of these foci is limited by the numbers of ticks sampled as well as the sampling locations. For accurate determination of TBEV foci, a very small meshed sampling design is needed (52). Additionally, the virus load in ticks can be below the detection limit (53); therefore, the lack of TBEV in the ticks in this study does not confirm the absence of TBEV in the sampling area.

This study showed that the distribution of tick-borne pathogens is frequently linked to the distribution of the main tick vector species, and surveillance of these pathogens must include the determination and examination of putative vector species in endemic and neighboring regions in order to prevent the spread of diseases. In Kosovo (and possibly also in Albania where only comparatively few ticks could be sampled), there is an eminent risk to contract CCHV and B. burgdorferi s. 1 . by tick bites, but the distribution of the pathogens and their vectors is uneven and detailed risk analyses require more detailed information on their distribution.

\section{AUTHOR CONTRIBUTIONS}

$\mathrm{KS}, \mathrm{AJ}$, and GD designed the study. AR, BM, KB, and $\mathrm{ZH}$ conducted the fieldwork. KS, RG, and GD conducted the laboratory work. All the authors contributed to the manuscript editing and approved the final manuscript.

\section{ACKNOWLEDGMENTS}

We would like to thank Dr. Petra Emmerich from the Bernhard Nocht Institute for Tropical Medicine, Hamburg for support in CCHFV diagnosis, as wells as Dr. Xhevat Jakupi and Florim Ahmeti from the National Institute of Public Health in Kosovo, Prishtina for providing patient data.

\section{FUNDING}

This study was supported by the Center for Social innovation (ZSI GmbH) Vienna, Austria (project no. K-02-2012) promoting Institutional Development Higher Education and Research in Kosovo (HIGHERKOS).

7. Kosovo National Institute of Public Health. (2016). Available from: http:// msh-ks.org/instituti-kombetar-i-shendetesise-publike/

8. Papa A, Velo E, Papadimitriou E, Cahani G, Kota M, Bino S. Ecology of the Crimean-Congo hemorrhagic fever endemic area in Albania. Vector Borne Zoonotic Dis (2009) 9:713-6. doi:10.1089/vbz.2008.0141

9. Sherifi K, Cadar D, Muji S, Robaj A, Ahmeti S, Jakupi X, et al. CrimeanCongo hemorrhagic fever virus clades V and VI (Europe 1 and 2) in ticks in Kosovo, 2012. PLoS Negl Trop Dis (2014) 8:e3168. doi:10.1371/journal. pntd.0003168

10. Ajazaj L, Ahmeti S, Halili B. Crimean-Congo hemorrhagic fever in Kosovo during epidemic in 2013 [in Albanian]. Proceedings of the 1th National Conference of CCHF in Kosovo. Malisheve, Kosovo (2015). 13 p.

11. Papa A, Velo E, Kontana A, Kadriaj P, Mersini K, Dhimolea M, et al. Proceedings of the First International Conference of CCHF, 13-14 February 2015. Thessaloniki, Greece (2015). 18 p.

12. Deyede VM, Khristova ML, Rollin PE. Crimean-Congo hemorrhagic fever J Virol (2006) 80:8834-42. doi:10.1128/JVI.00752-06 
13. Ozkaya E, Dincer E, Carhan A, Uyar Y, Ertek M, Whitehouse CA, et al. Molecular epidemiology of Crimean-Congo hemorrhagic fever virus in Turkey: occurrence of local topotype. Virus Res (2010) 149:64-70. doi:10.1016/j.virusres.2009.12.014

14. Gern L, Humair PF. Ecology of Borrelia burgdorferi sensu lato in Europe. In: Gray J, Kahl O, Lane RS, Stanek G, editors. Lyme Borreliosis: Biology, Epidemiology and Control. UK: CAB International (2002). p. 149-74.

15. Gylfe A, Bergström S, Lundström J, Olsen B. Reactivation of Borrelia infection in birds. Nature (2000) 403:724-5. doi:10.1038/35001663

16. World Health Organization. The Vector-Borne Human Infections of Europe, their Distribution and Burden of Public Health. (2004). Available from: http:// www.euro.who.int/_data/assets/pdf_file/0008/98765/e82481.pdf

17. Rudenko N, Golovchenko M, Grubhoffer I, Oliver JH. Updates on Borrelia burgdorferi sensu lato complex with respect to public health. Ticks Tick Borne Dis (2011) 2:123-8. doi:10.1016/j.ttbdis.2011.04.002

18. Stanek G, Reiter R. The expanding Lyme Borrelia-clinical significance of genomic species? Clin Microbiol Infect (2011) 17:487-93. doi:10.1111/j. 1469-0691.2011.03492.x

19. Hubálek Z. Epidemiology of Lyme borreliosis. Curr Probl Dermatol (2009) 37:31-50. doi:10.1159/000213069

20. Rauter C, Hartung T. Prevalence of Borrelia burgdorferi sensu lato genospecies in Ixodes ricinus ticks in Europe: a metaanalysis. Appl Environ Microbiol (2005) 71:7203-16. doi:10.1128/AEM.71.11.7203-7216.2005

21. Tappe J, Jordan D, Janecek E, Fingerle V, Strube C. Revisited: Borrelia burgdorferi sensu lato infections in hard ticks (Ixodes ricinus) in the city of Hannover (Germany). Parasit Vectors (2014) 7:441. doi:10.1186/1756-3305-7-441

22. Christova I, Van De Pol J, Yazar S, Velo E, Schouls L. Identification of Borrelia burgdorferi sensu lato, anaplasma and Ehrlichia species, and spotted fever group Rickettsiae in ticks from Southeastern Europe. Eur J Clin Microbiol Infect Dis (2003) 22:535-42. doi:10.1007/s10096-003-0988-1

23. Charrel RN, Attoui H, Butenko AM, Clegg JC, Deubel V, Frolova TV, et al. Tick-borne virus diseases of human interest in Europe. Clin Microbiol Infect (2004) 10:1040-55. doi:10.1111/j.1469-0691.2004.01022.x

24. Süss J. Tick-borne encephalitis: epidemiology, risk areas, and virus strains in Europe and Asia-an overview. Ticks Tick Borne Dis (2011) 2:2-15. doi:10.1016/j.ttbdis.2010.10.007

25. Gritsun TS, Lashkevich VA, Gould EA. Tick-borne encephalitis. Antivir Res (2003) 57:129-47. doi:10.1016/S0166-3542(02)00206-1

26. Dumpis U, Crook D, Oksi J. Tick-borne encephalitis. Clin Infect Dis (1999) 28:882-90. doi:10.1086/515195

27. Saikku P. Tick-borne viruses. Med Biol (1975) 53:317-20.

28. Labuda M, Stünzner D, Kozuch O, Sixl W, Kocianova E, Schäffler R. Tick-borne encephalitis virus activity in Styria, Austria. Acta Virol (1992) 37:187-90

29. Süss J, Klaus C, Diller R, Schrader C, Wohanka A, Abel U. TBE incidence versus virus prevalence and increased prevalence of the TBE virus in Ixodes ricinus removed from humans. Int J Med Microbiol (2006) 296(Suppl 40):63-8. doi:10.1016/j.ijmm.2005.12.005

30. Durmisi E, Knap N, Saksida A, Trilar T, Duh D, Avsic-Zupanc T. Prevalence and molecular characterization of tick-borne encephalitis virus in Ixodes ricinus ticks collected in Slovenia. Vector Borne Zoonotic Dis (2011) 11:659-64. doi:10.1089/vbz.2010.0054

31. Eltari E. Epidemiology of tick-borne encephalitis in Albania. Ellipse (1991) 29:449-50.

32. Eltari E, Gina A, Bitri T, Sharofi F. Some data on arboviruses, especially tickborne encephalithis, in Albania. G Mal Infett Parassit (1993) 45:404-11.

33. Report of the Kosovo Environmental Protection Agency. Report of the State of Nature 2008-2009. (2010). Available from: http://www.ammk-rks.net/ repository/docs/Raporti_Natyra_Eng.pdf. Accessed 30 January 2017

34. Ministry of Environment, Forestry and Water Administration in Albania. Albania's Second National Communication to the Conference of Parties under the United Nations Framework Convention on Climate Change. (2009). Available from: http://unfccc.int/resource/docs/natc/albnc2.pdf

35. Torina A, Khoury C, Carcappa S, Maroli M. Ticks infesting livestock on farms in western Sicily, Italy. Exp Appl Acarol (2006) 38:75-86. doi:10.1007/ s10493-005-5629-1

36. Estrada-Peña A, Bouattour A, Camicas JL, Walker AR. Ticks of Domestic Animals in the Mediterranean Region: A Guide to Identification of Species. Zaragoza: University of Zaragoza (2004). 131 p.
37. Regional O, Whitehouse CA. Crimean-Congo Hemorrhagic Fever - A Global Perspective. Dordrecht: Springer, Berlin (2007). 328 p.

38. Gunes T, Poyraz O, Vatansever Z. Crimean-Congo hemorrhagic fever virus in ticks collected from humans, livestock, and picnic sites in the hyperendemic region of Turkey. Vector Borne Zoonotic Dis (2011) 11:1411-6. doi:10.1089/ vbz.2011.0651

39. Orkun Ö, Karaer Z, Çakmak A, Nalbantoğlu S. Crimean-Congo hemorrhagic fever virus in ticks in Turkey: a broad range tick surveillance study. Infect Genet Evol (2017) 52:59-66. doi:10.1016/j.meegid.2017.04.017

40. Papa A, Tsioka K, Kontana A, Papadopoulos C, Giadinis N. Bacterial pathogens and endosymbionts in ticks. Ticks Tick Borne Dis (2017) 8:31-35. doi:10.1016/j.ttbdis.2016.09.011

41. Yurchenko OO, Dubina DO, Vynograd NO, Gonzalez JP. Partial characterization of tick-borne encephalitis virus isolates from ticks of southern Ukraine. Vector Borne Zoonotic Dis (2017) 17(8):550-7. doi:10.1089/vbz.2016.2094

42. Sprong H, Wielinga PR, Fonville M, Reusken C, Brandenburg AH, Borgsteede F, et al. Ixodes ricinus ticks are reservoir hosts for Rickettsia helvetica and potentially carry flea-borne Rickettsia species. Parasit Vectors (2009) 2(1):41. doi:10.1186/1756-3305-2-41

43. Heylen D, Fonville $M$, van Leeuwen A, Stroo A, Duisterwinkel M, van Wieren S, et al. Pathogen communities of songbird-derived ticks in Europe's low countries. Parasit Vectors (2017) 10(1):497. doi:10.1186/s13071-0172423-y

44. Dantas-Torres F, Otranto D. Species diversity and abundance of ticks in three habitats in southern Italy. Ticks and Tick Borne Dis (2013) 4:251-5. doi:10.1016/j.ttbdis.2012.11.004

45. Papa A, Chaligianis I, Kontana N, Sourba T, Tsioka K, Tsatsaris A, et al. A novel AP92-like Crimean-Congo hemorrhagic fever virus strain, Greece. Ticks and Tick Borne Dis (2014) 5:590-3. doi:10.1016/j.ttbdis.2014.04.008

46. Schuster I, Mertens M, Mrenoshki S, Staubach C, Mertens C, Bruning F, et al. Sheep and goats as indicator animals for the circulation of CCHFV in the environment. Exp Appl Acarol (2016) 68:337-46. doi:10.1007/s10493-015-9996-y

47. Palomar A, Aránzazu P, Santibáñez P, Mazuelas D, Arizaga J, Crespo A, et al. Crimean-Congo hemorrhagic fever virus from migratory birds, Morocco. Emerg Infect Dis (2013) 19:260-3. doi:10.3201/eid1902.121193

48. European Centre for Disease Prevention and Control. Crimean-Congo Haemorrhagic Fever in Spain - 8 September 2016. (2016). Available from: http://ecdc.europa.eu/en/publications/Publications/crimean-congohaemorrhagic-fever-spain-risk-assessment.pdf

49. Hewson R, Gmyl A, Gmyl L, Smirnova SE, Karganova G, Jamil B, et al. Evidence of segment reassortment in Crimean-Congo haemorrhagic fever virus. J Gen Virol (2004) 85:3059-70. doi:10.1099/vir.0.80121-0

50. Angelov L, Dimova P, Berbencova W. Clinical and laboratory evidence of the importance of the tick D. marginatus as a vector of B. burgdorferi in some areas of sporadic Lyme disease in Bulgaria. Euro J Epidemiol (1996) 12(5):499-502. doi:10.1007/BF00144003

51. Stefanoff P, Pfeffer M, Hellenbrand W, Rogalska J, Rühe F, Makówka A, et al. Virus detection in questing ticks is not a sensitive indicator for risk assessment of tick-borne encephalitis in humans. Zoonoses Public Health (2013) 60:215-26. doi:10.1111/j.1863-2378.2012.01517.x

52. Duscher GG, Wetscher M, Baumgartner R, Walder G. Roe deer sera used for TBE surveillance in Austria. Ticks Tick Borne Dis (2015) 6:489-93. doi:10.1016/j.ttbdis.2015.03.018

53. Belova OA, Burenkova LA, Karganova GG. Different tick-borne encephalitis virus (TBEV) prevalences in unfed versus partially engorged ixodid ticksevidence of virus replication and changes in tick behavior. Ticks Tick Borne Dis (2012) 3:240-6. doi:10.1016/j.ttbdis.2012.05.005

Conflict of Interest Statement: The authors declare that the research was conducted in the absence of any commercial or financial relationships that could be construed as a potential conflict of interest.

Copyright (C) 2018 Sherifi, Rexhepi, Berxholi, Mehmedi, Gecaj, Hoxha, Joachim and Duscher. This is an open-access article distributed under the terms of the Creative Commons Attribution License (CC BY). The use, distribution or reproduction in other forums is permitted, provided the original author(s) and the copyright owner are credited and that the original publication in this journal is cited, in accordance with accepted academic practice. No use, distribution or reproduction is permitted which does not comply with these terms. 